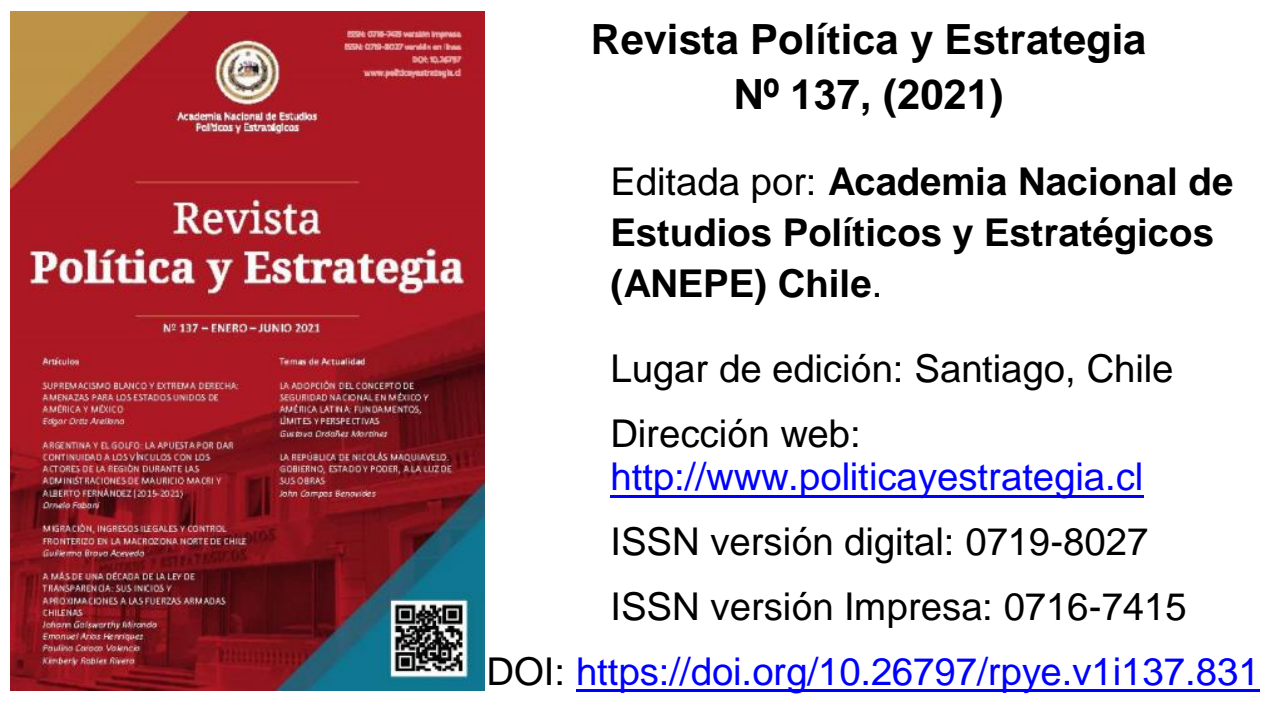

Para citar este artículo / To cite this article: BRAVO Acevedo, Guillermo: "Migración, ingresos ilegales y control fronterizo en la macrozona norte de Chile".

Revista Política y Estrategia No 137. 2021. pp. 69-92

DOI: https://doi.org/10.26797/rpye.v1i137.831

Si desea publicar en Política y Estrategia, puede consultar en este enlace las Normas para los autores:

To publish in the journal go to this link:

http://politicayestrategia.cl/index.php/rpye/about/submissions\#authorGuidelines

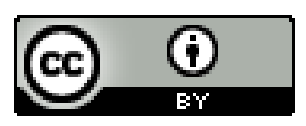

La Revista Política y Estrategia está distribuida bajo una Licencia Creative Commons Atribución 4.0 Internacional 


\title{
MIGRACIÓN, INGRESOS ILEGALES Y CONTROL FRONTERIZO EN LA MACROZONA NORTE DE CHILE $\infty$
}

GUILLERMO BRAVO ACEVEDO*

\begin{abstract}
RESUMEN
El análisis de los movimientos de población que se relacionan con los conceptos de frontera, límites y control de fronteras constituye el marco teórico de este artículo. En esta perspectiva, se exponen las políticas de control migratorio que aplica Chile cuando extranjeros solicitan cruzar las fronteras de la macrozona norte del país para radicarse en el territorio nacional. Adicionalmente, se describen las situaciones que han presentado los ingresos ilegales, por la vía de la trata de personas y el tráfico de migrantes ${ }^{1}$.
\end{abstract}

Palabras clave: Migraciones; Trata de personas; Tráfico de Migrantes; Control de Fronteras.

\section{MIGRATION, ILLEGAL INCOME AND BORDER CONTROL IN CHILE'S MACRO NORTH}

\begin{abstract}
The analysis of population movements that relate to the concepts of border, boundaries and border control is the theoretical framework for this article. In this perspective, Chile's migration control policies are set out when foreigners request to cross the borders of the macro northern part of the country to settle in the national territory. In addition, it describes the situations that have presented illegal income, through human trafficking and migrant trafficking1.
\end{abstract}

Key words: Migrations; Human Trafficking; Migrant Trafficking; Border Control.

* Dr. en Historia. Profesor Titular e Investigador del Centro de Investigaciones y Estudios Estratégicos de la Academia Nacional de Estudios Políticos y Estratégicos. gbravo@anepe.cl ORCID: https://orcid.org/00000001-5284-6794

1 Algunas ideas contenidas en este artículo fueron publicadas, como versión preliminar en un artículo de opinión, con el título "Chile ¿Migraciones sin fronteras?", en la Revista Migrante № 77, INCAMI. Santiago, enero 2020, pp. 33-36. Disponible en: https://incami.cl/wp-content/uploads/2020/04/Revista-Migrantes-No.-77.pd f

$\infty \quad$ Fecha de recepción: 180521 - Fecha de aceptación: 080621. 


\title{
MIGRAÇÃO, RENDA ILEGAL E CONTROLE DE FRONTEIRAS NO MACRO NORTE DO CHILE
}

\begin{abstract}
RESUMO
A análise dos movimentos populacionais que se relacionam com os conceitos de fronteira, limites e controle de fronteiras é o marco teórico deste artigo. Nessa perspectiva, as políticas de controle migratório do Chile são estabelecidas quando estrangeiros pedem para cruzar as fronteiras da parte macro norte do país para se estabelecerem no território nacional. Além disso, descreve as situações que apresentaram renda ilegal, através do tráfico de pessoas e do tráfico de migrantes1.
\end{abstract}

Palavras-chave: Migração; Tráfico de Pessoas; Tráfico de Migrantes; Controle de Fronteiras.

\section{INTRODUCCIÓN}

La migración, como movimiento de población, siempre ha estado asociada a la historia del hombre. La razón de esta asociación se encuentra en que los hombres impulsados por la búsqueda de mejores condiciones de vida, bienestar social y económico se han trasladado de un lugar a otro constantemente. Sin embargo, la migración internacional en la actual sociedad del siglo XXI tiene otro perfil debido a los cambios producidos por el dinamismo económico y la multidimensionalidad del proceso de globalización. Así, los flujos migratorios presentan diversas modalidades, se han complejizado y son factores de gran importancia en la construcción de la multiculturalidad en las sociedades receptoras.

La globalización y la economía con base mundial han provocado importantes cambios en los movimientos de población, observándose en América Latina verdaderas diásporas que, de una u otra forma, han producido transformaciones en las políticas migratorias de varios países de la región. El principal impacto que han causado estos flujos migratorios se refiere a que las políticas migratorias: “...se han enfrentado al dilema entre el control fronterizo, como medida de soberanía nacional, y el derecho a la emigración, como derecho humano"2.

En este contexto, el corpus del texto especificará, en primer lugar, las premisas teóricas relacionadas con los movimientos de población, para seguir luego con los conceptos de frontera, límites y control de fronteras. A continuación, precisará algunos de los aspectos de la política migratoria nacional y su asociación con la nueva migración, la situación de la trata de personas, el tráfico de migrantes y el control de fronteras en Chile. 


\section{DIMENSIONES TEÓRICAS: MOVIMIENTOS DE POBLACIÓN Y CONTROL DE FRONTERAS}

Los movimientos migratorios han sido un fenómeno social y económico permanente en la historia del hombre; antecedente que explica porque se han transformado en uno de los factores de mayor impacto multidimensional, sobre todo, en el marco de la migración internacional motivada por razones económicas, sociales, políticas y culturales. Dichos movimientos han llevado a millones de personas a trasladarse continentalmente $o$, a pasar de un país a otro. En la actualidad los flujos migratorios se han integrado estructuralmente a la globalización y a la mundialización de la economía generando transformaciones significativas en la realidad mundial tanto en aspectos geopolíticos y geoeconómicos, como particularmente en las dimensiones económicas, sociales, políticas y culturales ${ }^{3}$.

Por otra parte, desde fines del siglo XX los desplazamientos de población aumentaron significativamente; situación que impactó el proceso migratorio $y$, desde luego, complejizó los trámites en el control de fronteras que dificultaban la libre circulación. Ante este problema la Organización Internacional para las Migraciones (OIM) señala que los países se enfrentaron a un reto común: "facilitar el movimiento legítimo de personas y bienes al tiempo que se mantiene la seguridad de las fronteras" ${ }^{4}$, pero controladas al mismo tiempo. En otras palabras, a estos países se les planteaba el siguiente dilema: al considerar la emigración como un derecho humano, se establece una contradicción con los derechos del Estado, el que reconoce que la inmigración es una cuestión de soberanía nacional.

Analizada la situación desde la perspectiva de la seguridad, el problema para los Estados sería determinar si el fenómeno migratorio, como factor de cambios histórico-sociales, afectaría su soberanía si sus fronteras internacionales se mantuviesen abiertas para acoger a los migrantes para no vulnerar sus derechos humanos.

La clave, de todas maneras, estaría en la regulación legal que se utilice. Si la política migratoria implementada por un Estado contiene normas que autoricen el paso libre a todos aquellos migrantes que quieran ingresar a su territorio, se entiende que está aceptando abiertamente que se reconoce a la emigración como un derecho humano. Caso contrario, si la legislación migratoria establece normas de control fronterizo que regulen el ingreso de personas, principalmente, para prevenir la migración irregular se está reconociendo que la soberanía nacional es un derecho del Estado que está por sobre el derecho a la emigración.

En el fondo, la legislación migratoria de los países debería mantener un equilibrio entre ambos derechos puesto que el derecho a la libertad de movimiento de las personas se consagra en el artículo 13 de la Declaración Universal de los Derechos Humanos de 1948 con las siguientes palabras, "Toda persona tiene derecho a circular libremente y a elegir su residencia en el territorio de un Estado $»^{5}$, en tanto que los derechos del Estado se identifican como un principio de gobernanza, establecido en su Constitución y aplicado

3 BRAVO. (2020) Loc. Cit.

4 ORGANIZACIÓN INTERNACIONAL PARA LAS MIGRACIONES (OIM). Inmigración y gestión de fronteras. (2021). Disponible en: https://www.iom.int/es/inmigracion-y-gestion-de-fronteras

5 ORGANIZACIÓN DE LAS NACIONES UNIDAS (ONU). Declaración Universal de los Derechos Humanos 1948. En: Museo de la Memoria y los Derechos Humanos. Área de Educación. Santiago. Disponible en: http://www.museodelamemoria.cl/wp-content/uploads/2011/09/DECLARACIÓN-UNIVERSAL-DE-LOS-DERECHOS-HUMANOS.pdf 
con independencia; principio reconocido en la Carta de las Naciones Unidas, en su Capítulo I, artículo 1.2. que establece: "Fomentar entre las naciones relaciones de amistad basadas en el respeto al principio de la igualdad de derechos y al de la libre determinación de los pueblos, y tomar otras medidas adecuadas para fortalecer la paz universal"6.

Desde el punto de vista teórico habría que determinar, entonces, que "la emigración se reconoce como un derecho humano, en tanto que la inmigración es una cuestión de soberanía nacional"7.

La Organización Internacional para las Migraciones (OIM) señala que el concepto migración se refiere a un movimiento de población "...hacia el territorio de otro Estado o dentro del mismo que abarca todo movimiento de personas sea cual fuere su tamaño, su composición o sus causas" ${ }^{\prime}$.

El concepto emigración está definido por la OIM como el "Acto de salir de un Estado con el propósito de asentarse en otro", en tanto que el de inmigración se refiere a un "Proceso por el cual personas no nacionales ingresan a un país con el fin de establecerse en él"

Analizados los conceptos de inmigración y emigración se puede inferir que no existe una diferencia fundamental entre ellos, lo que permite generalizar estableciendo que ambos se reconocen como un movimiento de población que permite a las personas trasladarse de un punto a otro libremente ${ }^{10}$. En consecuencia, la emigración es el derecho que tiene "...cualquier ciudadano de abandonar su suelo natal, en tanto que la inmigración no le garantiza a esa misma persona la entrada a otro país porque ese ingreso puede estar regulado por la política migratoria de ese país"11.

Los conceptos de frontera, límites y control fronterizo son elementos principales al momento de definir la soberanía de un país. Astrid Espaliat, citando a Caflisch, señala que "...la frontera puede ser definida como la línea que separa los territorios terrestres sobre los que los ESTADOS ejercen la soberanía de todo el territorio"12. En otros términos, este concepto se entiende como una línea convencional que marca el confín del territorio de un Estado y, por lo tanto, alude a que el gobierno de un país tiene soberanía sobre los territo-

6 ONU. Carta de las Naciones Unidas. 1945. Disponible en https://www.un.org/es/sections/un-charter/chapter-i/index.html

7 PÉCOUD, Antoine y GUCHTENEIRE, Paul de. Migración sin fronteras: una investigación sobre la libre circulación de personas. En: Migraciones Internacionales, vol. 3, 2, UNESCO. 2005. p. 145. Disponible en: https://migracionesinternacionales.colef.mx/index.php/migracionesinternacionales/article/view/1218

8 OIM, Glosario sobre Migración. En Derecho Internacional sobre Migraciones № 7. Ginebra. 2006. p. 7. Disponible en: https://publications.iom.int/system/files/pdf/iml_7_sp.pdf

9 OIM. (2006). Op. Cit. pp. 23-32.

10 Del mismo modo, a lo largo del texto, los conceptos migrante e inmigrante se consideran como sinónimos, considerando que ambos corresponden a una persona que migra.

11 BRAVO. (2020). Op. Cit. p. 34.

12 ESPALIAT Larson, Astrid. Fronteras y límites. Una mirada desde el Derecho Internacional. Instituto de Estudios Internacionales. Universidad de Chile. 2011. Disponible en http://iei.uchile.cl/noticias/70662/fronteras-y-limites-una-mirada-desde-el-derecho-internacional 
rios que están dentro de sus fronteras. Por otra parte, el concepto límite está definido por la RAE como "Línea real o imaginaria que separa dos terrenos, dos países, dos territorios"13.

La noción de frontera ha tenido diversas aplicaciones a través de la historia. Una de las más importantes es la hipótesis planteada por Frederick Jackson Turner en 1893, para la colonización del Gran Oeste, que se transformó en una herramienta metodológica para interpretar la historia de Estados Unidos. Otros historiadores también han utilizado interpretaciones para historiar temas de frontera: A. Lewis para la sociedad medieval sobre el cierre de fronteras y las de Ray Allen Billington para el establecimiento europeo en el continente americano, o la de J.A. Maravall que indica que lo único permanente de la frontera de los estados hispánicos durante ocho siglos fue precisamente su falta de permanencia ${ }^{14}$.

Considerando otro punto de vista, Baggio sostiene que el concepto de frontera es amplio y que se pueden reconocer las fronteras nacionales, cuyo objetivo es detener la inmigración irregular utilizando controles de seguridad que impidan el cruce de migrantes; las llamadas fronteras externalizadas, utilizadas por los países receptores para acordar con los países de tránsito el control de las corrientes migratorias hacia su territorio; y finalmente, las fronteras internalizadas, por medio de las cuales las autoridades y las personas utilizan diversas formas que dificultan la integración de los migrantes ${ }^{15}$.

De las interpretaciones mencionadas podría deducirse que el concepto de frontera suele utilizarse en algunas ocasiones como sinónimo de límite. Sin embargo, como acota Briceño Monzillo, técnicamente, "...existen diferencias entre ambos, pues la idea de limites responde a una noción lineal, en cambio la frontera, a una noción espacial que involucra, por tanto, no solo el límite sino también a toda la zona delimitada por éste"16.

También, el significado del término frontera se puede ampliar incorporando algunos adjetivos, pero esta acción implica que la interpretación del concepto cambie radicalmente. Para el caso de este artículo si se agrega al vocablo frontera la palabra "política", se tiene una nueva proposición, "frontera política", que se reconoce como "...una institución cuya dimensión histórica es la de constituir el punto de equilibrio entre el territorio, la nación y el Estado"17.

13 DICCIONARIO DE LA REAL ACADEMIA (RAE). 2019. Disponible en: https://dle.rae.es/l\%C3\%ADmite

14 NORAMBUENA, Carmen. "Frontera, Fronteras, Límites y Trasgresiones": En: Cuadernos de Historia № 20. Universidad de Chile. Santiago. 2000, pp. 124-126.

15 BAGGIO, Fabio. Fronteras nacionales, internalizadas y externalizadas. En: ANGUIANO Téllez, María Eugenia y LÓPEZ Sala, Ana María (Eds). Migraciones y fronteras: nuevos contornos para la movilidad internacional, Barcelona, Icaria Antrazyt/CIDOB, 2010, pp. 49-74.

16 BRICEÑO Monzillo, José Manuel. Nuestras fronteras con Colombia. Universidad de Los Andes. Mérida. 1982, p. 130.

17 RANFLA González, Arturo. Frontera política y espacio fronterizo. En: Estudios Fronterizos Año II, Vol. I, № 4-5. Instituto de Investigaciones Sociales. Universidad Autónoma de Baja California. 1984. p 50. Disponible en: http://ref.uabc.mx/ojs/index.php/ref/article/view/383 
En suma, desde la perspectiva teórica el límite debería entenderse como la separación entre dos fronteras, en tanto que la frontera se refiere al espacio en que se ponen en contacto los territorios de dos o más soberanías asumiendo la acepción de límite ${ }^{18}$.

Entonces, si existen zonas o espacios fronterizos o territorios limítrofes en los que se encuentran poblaciones que conviven social y económicamente, la zona de frontera se convierte en un espacio de convivencia social de múltiples intercambios ${ }^{19}$.

Los habitantes de esas zonas fronterizas cruzan constantemente los límites e ingresan a los territorios vecinos no teniendo intención de radicarse en ellos; situación que se manifiesta en muchos espacios limítrofes sin control fronterizo, como, por ejemplo, la denominada frontera Andina del norte de Chile, en la que conviven tres comunidades andinas: Anconamarca, Charaña y Visviri ${ }^{20}$. Sin embargo, la situación cambia cuando hay personas que no viven permanentemente en esas zonas de frontera y cruzan el límite con el propósito de formalizar una permanencia definitiva. Entonces, se estaría frente a un movimiento migratorio irregular porque "...el migrante no tiene la autorización necesaria ni los documentos requeridos por las autoridades de inmigración para ingresar, residir o trabajar en un determinado país" ${ }^{21}$.

Asimismo, el cruce de frontera por medio del sistema de trata de personas o de tráfico de migrantes también se configura como un movimiento de población, pero con características puntuales. Si bien es cierto que los conceptos migración, trata de personas y tráfico de migrantes tienen significados que los diferencian, también es cierto que presentan una relación porque la palabra migración, definida por la OIM las incluye al señalar que es un movimiento de población hacia el territorio de otro Estado, que “...incluye migración de refugiados, personas desplazadas, personas desarraigadas, migrantes económicos"22. En este marco, el concepto migración se entiende como polisémico pues incluye toda clase de movimiento de personas y, dentro de esos movimientos están la trata de personas y el tráfico de migrantes.

Precisamente, la persistencia de estos movimientos que son difíciles de controlar porque están bajo la conducción de grupos y mafias internacionales que actúan sigilosamente y la continua presencia de migrantes indocumentados en las fronteras, ponen en jaque a los Estados frente al control de sus fronteras, razón por la que "El control de la inmigración se ha convertido en un importante ámbito normativo. La mayoría de los Estados

18 NORAMBUENA. (2000). Op. Cit. p. 129.

19 Por ejemplo, esto podría suceder entre el paso fronterizo Colchane-Pisiga, en la frontera entre Chile y Bolivia ubicado en plena cordillera de Los Andes a 3.690 metros de altura.

20 GONZÁLEZ Miranda, Sergio. La voz desde Lejos. La triple-frontera andina: Entre la heterología y la globalización. En: Andamios. Revista de Investigación Social. Vol. 12. № 28. Colegio de Humanidades y Ciencias Sociales, Universidad Autónoma de la Ciudad de México. Disponible en: http://www.scielo.org.mx/pdf/ anda/v12n28/1870-0063-anda-12-28-00019.pdf 2015, En la Frontera Andina "...la existencia de estas tres comunidades andinas, Ancomarca, Charaña y Visviri, en dicha franja trifronteriza ha dependido de las decisiones de la diplomacia, también sus respectivas nacionalidades han dependido de esas decisiones". p. 21.

21 OIM. (2006). Op. Cit. p. 40. El Glosario sobre Migración citado considera que el concepto de "migración ilegal" es equivalente con el de "migración irregular". p. 39. Asimismo, define que un "migrante ilegal" también se puede definir como "migrante irregular". pp. 42-43. 
receptores sienten gran inquietud por la porosidad de sus fronteras y están estableciendo nuevas medidas para controlarlas" ${ }^{\prime 23}$.

La dinámica de los actuales flujos migratorios internacionales ha determinado que las autoridades de gobierno tengan un desafío con dos frentes, por un lado, deben asegurar que exista un puesto donde se puedan fiscalizar actividades relacionadas con lo económico y lo social bajo el parámetro del tránsito legal de personas y bienes y servicios y, por otro, proteger las fronteras del crimen organizado que, como empresa, sigue el ritmo general de la economía globalizada.

En esta perspectiva, "Estas actividades del crimen organizado se concentran en las zonas fronterizas, al igual que los flujos migratorios. La consecuencia es que, a veces, la migración se incluye en el conjunto de problemas de seguridad que asolan a las fronteras" ${ }^{\prime 24}$.

En cuanto al Control Fronterizo o Control de Fronteras, en el caso de Chile, se puede decir que la responsabilidad recae en una unidad gubernamental encargada de solicitar los documentos de identidad y otros que están señalados en la legislación migratoria a las personas que desean ingresar al territorio nacional. Esta unidad, una vez que revisa la documentación, autoriza la entrada de esas personas, en calidad de turistas o con visa de trabajo, según sea la situación migratoria. Posteriormente, la calidad de residente corresponde a otra unidad administrativa. Con esta gestión, presta asistencia a las autoridades migratorias del país y controla que las personas no se conviertan en migrantes indocumentados.

\section{CHILE: POLÍTICAS MIGRATORIAS EN EL SIGLO XXI}

Las migraciones internacionales asociadas a la globalización irrumpieron con mucha fuerza en el horizonte de todos los países del mundo a fines del siglo XX, pero en los primeros veinte años del siglo XXI, el aumento constante de los flujos migratorios ha provocado múltiples cambios en las sociedades de las que han salido los migrantes y, también, en aquellas que los han recibido.

Para el caso de Chile, el equilibrado desarrollo y crecimiento de la economía nacional, desde la vuelta a la democracia, permitió que el país se transformara en una sociedad receptora estable, acogedora y atractiva para la migración regional, lo que provocó una modificación del perfil de los migrantes que fueron llegando al territorio nacional. A partir de 1982 el flujo migratorio considerado como tradicional, compuesto principalmente por ciudadanos europeos, tuvo un vuelco importante porque la inmigración extranjera que llegó al país se distinguía “...por provenir de países latinoamericanos" ${ }^{25}$. Las estadísticas comprueban esta afirmación, pues según los datos del censo de 1982 el porcentaje de europeos

23 PÉCOUD y GUCHTENEIRE. (2005). Op. Cit. p. 139.

24 ARMIJO Canto, Natalia. Introducción. En: N. Armijo Canto (Ed.) Migración y seguridad: nuevo desafío en México. Colectivo de Análisis de la Seguridad con Democracia A.C. (CASEDE). Disponible en: https://www. casede.org/PublicacionesCasede/MigracionySeguridad/pda.pdf, México. 2011, p. 7.

25 BRAVO, Guillermo. La política migratoria de Chile en tiempos de la globalización y la "Nueva Migración”. En: Desafíos de la Seguridad y Defensa en el mundo contemporáneo. Libro Colección ANEPE No 39. Santiago. 2016, p. 293 Disponible en: https://anepe.cl/wp-content/uploads/2020/10/LIBRO-ANEPE-39.pdf 
alcanzó a $31.8 \%$ y el de latinoamericanos a 54.5\%; en tanto que los datos del censo de 2012, para los mismos indicadores fue de $10.5 \%$ y $80.6 \%$, respectivamente ${ }^{26}$.

Las estadísticas de las Naciones Unidas también destacan que Chile se convirtió en una sociedad receptora atractiva. Entre los años 2000 y 2017, “...los países o zonas que experimentaron las tasas de crecimiento más rápidas durante este periodo fueron Angola, Qatar y Chile"27.

La población extranjera que vivía en el país según los datos de los censos de 1992, 2002 y 2012 y la estimación para antes del censo del año 2017 alcanzaban las siguientes cifras: $114.597,184.464,339.536$ y 600.000 , respectivamente. Por tanto, “...la población extranjera que se ha radicado en Chile, entre 1992 y 2017, ha crecido en 423.6\%, en tanto que la población nacional creció en $31.7 \%$ en ese mismo período" ${ }^{28}$.

Los datos estadísticos demuestran el crecimiento que ha tenido el flujo migratorio en los últimos años. La Tabla № 1 muestra el cuadro comparativo del crecimiento porcentual de los migrantes que han llegado a Chile entre los años 2014 y 2017, destacando el aumento de la migración por nacionalidades.

\section{TABLA № 1}

Extranjeros en Chile por Nacionalidad y Año

\begin{tabular}{|l|c|c|c|}
\hline Nacionalidad & Estadística 2014 & Estadística 2017 & Aumento \% \\
\hline Perú & 130.329 & 249.389 & $91,4 \%$ \\
\hline Colombia & 25.038 & 126.981 & $407,2 \%$ \\
\hline Bolivia & 36.036 & 111.011 & $208,1 \%$ \\
\hline Venezuela & 8.001 & 84.056 & $950,6 \%$ \\
\hline Haití & 1.649 & 73.098 & $4332,9 \%$ \\
\hline Argentina & 66.899 & 85.724 & $28,1 \%$ \\
\hline Ecuador & 19.133 & 35.678 & $86,5 \%$ \\
\hline Estados Unidos & 12.799 & 19.161 & $49,7 \%$ \\
\hline Otros & 116.144 & 180.735 & $55,6 \%$ \\
\hline Totales & 416.028 & 965.833 & $132,2 \%$ \\
\hline
\end{tabular}

Fuente: La Tercera. Gobierno cifra en más de un millón el número de inmigrantes que están en Chile. http:// www.latercera.com/nacional/noticia/gobierno-cifra-mas-millon-numero-inmigrantes-estan-chile/121733/ pp. 14-15. La suma correcta para el total de extranjeros del año 2017 es 965.833 y no 966.363 , como se publica en la fuente. Los cálculos del aumento porcentual de extranjeros son nuestros.

26 INSTITUTO NACIONAL DE ESTADÍSTICAS (INE). Censos de Población 1982-2012. Disponible en: www.http://historico.ine.cl/canales/chile_estadistico/censos/censo_poblacion_vivienda.php 1982-2012

27 ONU. International Migration Report 2017. p. 7 Disponible en: https://www.un.org/en/development/desa/population/migration/publications/migrationreport/docs/ MigrationReport2017_Highlights.pdf

28 BRAVO, Guillermo y NORAMBUENA, Carmen. Procesos Migratorios en Chile. Una mirada histórica normativa. Libro Colección ANEPE № 43. Santiago. 2018, p. 90. Disponible en: https://anepe.cl/wp-content/ uploads/2020/10/LIBRO-ANEPE-43.pdf 
La inmigración de latinoamericanos que llegó al país durante los últimos 40 años se enfrentó con una ley migratoria dictada en 1975, en un panorama político, social y económico muy diferente. Esta ley migratoria de carácter administrativo y burocrático, vigente a diciembre 2020, estableció normas que regulaban el ingreso de extranjeros a Chile, además, de los requisitos para obtener residencia y permanencia; las condiciones para salidas y reingresos, los factores determinantes de la expulsión y el control efectivo sobre todo lo relativo a los migrantes ${ }^{29}$, no fue efectiva para controlar el flujo migratorio que con el paso de los años creció sustantivamente, como lo han demostrado los datos estadísticos precedentes.

Ante el escenario de este nuevo perfil migratorio, cada gobierno decidió aplicar diversas políticas públicas que establecieron soluciones específicas a los problemas públicos que presentaba la migración en el país. En otras palabras, cada gobierno organizó un programa de regularización como la respuesta que el Estado daba a las demandas sociales de la migración para migrantes residentes en forma irregular. Consideradas en su conjunto, las políticas y los programas públicos aplicados trataron de adaptar la llamada Ley de Extranjería, dictada en 1975, a la realidad de la nueva migración que llegó a Chile.

En una rápida mirada, las políticas y los programas de regularización comenzaron por respetar las garantías que la Constitución establece y tomaron como base la ley de 1975. De esta forma, en el gobierno de Patricio Aylwin se aplicó un programa para el retorno de los chilenos en el exilio y otro programa sobre protección de todos los trabajadores migrantes y sus familias. Luego, en el gobierno de Eduardo Frei Ruiz-Tagle se inició el programa denominado "amnistía provisoria" que regularizó la permanencia de alrededor de 44.000 migrantes con permiso de residencia temporal y otorgó 18.000 permisos de permanencia definitiva ${ }^{30}$.

Las políticas aplicadas iniciaron las soluciones que formalizaron el proceso de regularización. De este modo, a inicios del siglo XXI, bajo la presidencia de Ricardo Lagos, se aplicaron medidas orientadas en tres ejes: hacer de Chile un país receptivo y abierto a la inmigración; regularización de los inmigrantes ilegales ligada fundamentalmente a la distorsión laboral, por la informalidad de la contratación; los inmigrantes regulares o irregulares deberán tener similares derechos que los nacionales ${ }^{31}$.

En el primer gobierno de Michelle Bachelet se dictó la Instrucción 009 del Gabinete Presidencial, de 02-09.2008, para la aplicación de la ley de extranjería, teniendo presente que se recogiera la realidad actual de Chile como país receptor de cuotas significativas de inmigrantes. De este modo, este instructivo declara en el numeral 6, letra a, que Chile es un país de acogida; en el numeral 7 , letra a, señala los principios de la Política Nacional

29 BIBLIOTECA CONGRESO NACIONAL (BCN). Gobierno de Chile. Decreto Ley N 1094, D.O. 19 de julio de 1975. Disponible en:

https://www.bcn.cl/leychile/navegar?idNorma=6483\&idVersion=2011-04-08\&buscar=1094

30 BRAVO y NORAMBUENA. (2018). Op. Cit. pp. 102-103.

31 ESCOBAR, Leyla. La inmigración en Chile: La necesidad de un Plan Nacional de Integración. y Cooperación Internacional. Diario Constitucional.cl. Santiago. (s.f.) Disponible en:

https://www.diarioconstitucional.cl/articulos/la-inmigracion-en-chile-la-necesidad-de-un-plan-nacional-de-integracion-y-cooperacion-internacional/ 
Migratoria, entre los que destacan la residencia y libertad de circulación; libertad de pensamiento y conciencia; acceso a la justicia; derechos laborales, entre otros ${ }^{32}$.

En la primera presidencia de Sebastián Piñera, se dictó la ley № 20.430 que estableció disposiciones sobre protección de refugiados y por el decreto 837 se aprobó el reglamento de la mencionada ley. Para la aplicación de estas normas se estableció que "se entenderá por "solicitante de la condición de refugiado" todo extranjero que se encuentre en el territorio nacional y formalice su intención de ser reconocido como refugiado, de acuerdo con lo establecido en los artículos 36 y 37 del presente reglamento" ${ }^{\prime 33}$.

Por otra parte, en el segundo gobierno de Michelle Bachelet y en el actual de Sebastián Piñera se dictaron una serie de decretos cuya finalidad era modernizar las políticas migratorias en tanto se aprobarán los proyectos enviados, por cada mandatario, al Congreso Nacional que actualizarían la ley de 1975.

Las políticas generadas por cada gobierno se aplicaron y el fenómeno migratorio se consideró asociado al reconocimiento de los derechos humanos, a la multiculturalidad, al respeto a la diversidad evitando la discriminación y promoviendo la igualdad de derechos, teniendo presente que la sociedad chilena se había convertido en una sociedad receptora de personas de diferentes países y contextos culturales como consecuencia de movimientos migratorios generalizados.

De pronto, la sociedad chilena tuvo que enfrentar un complejo proceso de aculturación entre la identidad nacional y las diversas identidades transnacionales. Al respecto, es necesario precisar que en las sociedades de acogida la asimilación y el multiculturalismo se han transformado en un proceso "...en donde los migrantes y sus descendientes crean nuevas identidades con aspectos tanto de la sociedad de destino como de la de origen; pero no de manera disonante, sino como una unidad propia ("ni de aquí, ni de allá)"'"34. En otras palabras, el inmigrante abandona su identidad originaria adoptando un nuevo rol social estableciéndose dentro de la sociedad receptora como ciudadano.

32 GOBIERNO DE CHILE. Gabinete de la Presidencia. Imparte instrucciones sobre la Política Nacional de Migraciones 2 de septiembre de 2008 Disponible en: https://www.extranjeria.gob.cl/media/2019/03/Inst-Presidencial-No-9.pdf

33 BIBLIOTECA DEL CONGRESO NACIONAL. (BCN). Ministerio del Interior. Subsecretaría del Interior. Aprueba Reglamento de la Ley № 20.430, que establece disposiciones sobre protección de refugiados. 2011. Disponible en: https://www.extranjeria.gob.cl/media/2019/03/DTO-837_17-FEB-2011_Reglamento_Refugio.pdf

34 BRETONES, F. D. y GONZÁLEZ-GONZÁLEZ, J. M. “Identidad y migración: la formación de nuevas identidades transculturales", En: H. M. Cappello y M. Recio (Ed). La Identidad Nacional. Sus Fuentes Plurales de Construcción. Plaza y Valdés Editores. México. 2011, p. 143. Además, Según los autores "el concepto de aculturación ha ido deviniendo con el tiempo como un sinónimo de asimilación, es decir, donde la persona inmigrante abandona su identidad originaria adoptando el nuevo rol social". p. 142. Disponible en: https://www.academia.edu/4577111/Identidad_y_migraci\%C3\%B3n_la_formaci\%C3\%B3n_de_nuevas_ identidades_transculturales 


\section{CONTROL DE FRONTERAS Y MOVIMIENTOS DE POBLACIÓN}

Las políticas y programas públicos que orientaron la regularización de los migrantes en situación irregular y que fueron aplicadas sistemáticamente por los gobiernos de los últimos 30 años, también se encontraron con movimientos de población asociados a los flujos migratorios corrientes. Estos nuevos movimientos, como la trata de personas y el tráfico de migrantes, también impactaron los controles fronterizos de acceso al territorio nacional.

Estos programas que proponían una renovada política migratoria fueron recogidos por el Libro de la Defensa 2010, el que reconoció que a partir del año 2008 la política para atender a la "nueva migración" debería considerar los siguientes criterios: Chile es un país de acogida, abierto a la inmigración, que debe integrar y aceptar positivamente al migrante dentro de la sociedad, para lo cual debe generar acuerdos internacionales entre países de origen y de acogida, no renunciando a su derecho de un marco jurídico que oriente la entrada al territorio cuando sea inevitable. Por otro lado, deberá promover la migración segura previniendo y sancionando el tráfico ilícito de inmigrantes y, al mismo tiempo, establecer condiciones claras para asilados y refugiados ${ }^{35}$.

Frente al dilema de aceptar migraciones sin frontera, las estrategias que orienten la renovación de la política migratoria del país deben estar en armonía con el actual carácter que han asumido las migraciones en el marco de un mundo de globalización económica. En el fondo significa que la política migratoria nacional deberá asumir una actitud de protección de los derechos humanos para los migrantes. Pero, al mismo tiempo, deberá proteger la soberanía del país instalando requisitos para controlar y cautelar la entrada, permanencia y tránsito de los migrantes por el territorio chileno buscando un equilibrio con los derechos y deberes que el derecho internacional otorga a los migrantes ${ }^{36}$.

Sin embargo, uno de los problemas que está presente en la actual realidad de las migraciones internacionales y regionales, que también preocupa al Estado de Chile, por su directa relación con los derechos humanos, es el tráfico de migrantes y la trata de personas. Situación grave que pone en la disyuntiva al país en torno a aplicar, en algunas ocasiones, la legislación nacional no atendiendo a lo dispuesto a los convenios internacionales.

En las dos primeras décadas del siglo XXI el aumento continuo de la llegada de población extranjera a Chile, la facilidad para la entrada al territorio nacional y para el cruce de fronteras convirtieron al país en un destino atractivo para los migrantes transfronterizos y regionales; situación que ha facilitado que a los extranjeros que ingresan al país legalmente, en calidad de turistas, y que con el paso del tiempo se convierten en migrantes irregulares o indocumentados, se sumen a aquellos migrantes que son producto del tráfico de migrantes y de la trata de personas. De esta forma, las fronteras se convierten en un eje vulnerable para la seguridad interna, tanto por los pasos habilitados como por los no habilitados.

Chile no escapa a este problema mundial sobre la trata de personas. El Trafficking in Persons Report 2020, elaborado por el Departamento de Estado de Estados Unidos, describe el perfil del tráfico señalando que Chile es un país de origen, tránsito y destino para

35 MINISTERIO DE DEFENSA NACIONAL. Libro de la Defensa. Santiago. 2010. pp. 72-73.

36 Esta situación ha quedado patente con la crisis migratoria actual en América Latina provocada por el flujo masivo de migrantes y refugiados provenientes de Venezuela. 
hombres, mujeres y niños sometidos a trata sexual y trabajo forzoso. Señala, además, que la mayoría de las víctimas de trata entraron en Chile con visas de turista, y que las autoridades identificaron a dos víctimas, en 2019 , que entraron ilegalmente en el país. Por otra parte, dice el informe, que las autoridades comprobaron que los migrantes, especialmente, los ciudadanos venezolanos indocumentados o irregulares, están cada vez más en riesgo de caer en las redes de tráfico de migrantes debido a leyes de visados más estrictas promulgadas en junio de $2019^{37}$.

La información contenida en el Trafficking in Persons Report 2020, establece que los traficantes explotan a hombres, mujeres y niños - principalmente de otros países de América Latina, así como de Asia - en el trabajo forzoso en Chile en los sectores de la industria minera; la agricultura; la construcción; la venta ambulante; las actividades de los servicios generales; y el servicio doméstico. Los traficantes someten a inmigrantes chinos y haitianos a la trata sexual y al trabajo forzoso y a las mujeres colombianas a la trata sexual ${ }^{38}$.

No obstante, asegura el informe del Departamento de Estado que el Gobierno de Chile cumple plenamente con las normas mínimas para la eliminación del tráfico y trata de migrantes, demostrando esfuerzos sostenidos durante el período que abarca el informe. En consecuencia, Chile se ha mantenido con la calificación más alta, TIER 1 (Nivel 1), desde 2013.

\section{Gráfico № 1}

\section{Ranking Tier de Chile por año}

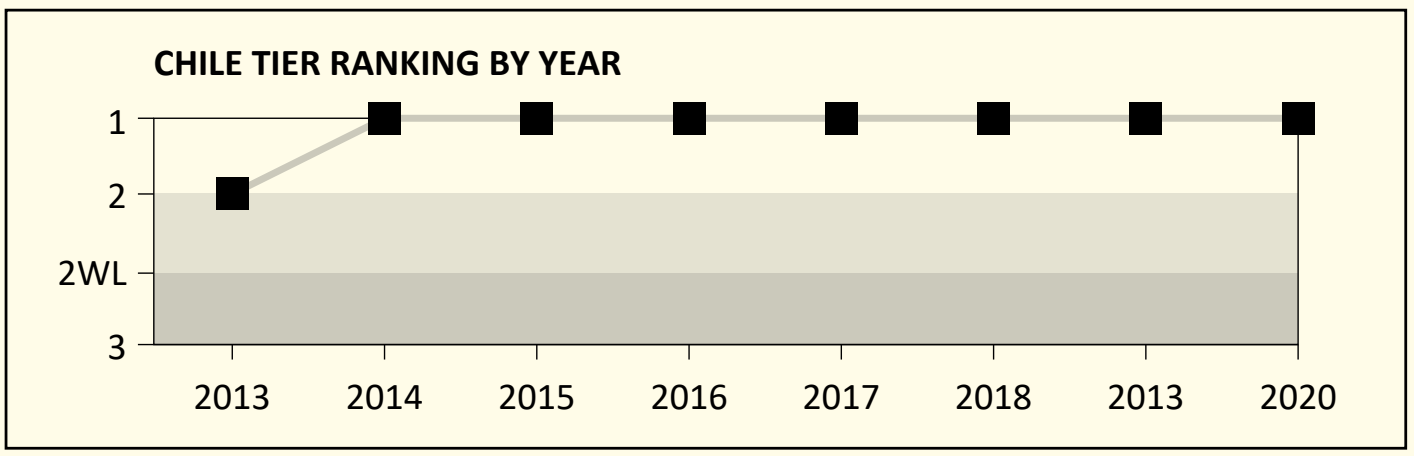

Fuente: Department of Estate. United States of América. Trafficking in Persons Report 20th Edition

Los datos analizados por el informe del Departamento de Estado concuerdan con las estadísticas de la Mesa Intersectorial Trata de Personas, del Ministerio del Interior de Chile. Las estadísticas indican que "Del total de 285 personas identificadas como víctimas de trata

37 DEPARTMENT OF ESTATE. United States of America. Trafficking in Persons Report 20th Edition. 2020. p. 151. Disponible en: https://www.state.gov/wp-content/uploads/2020/06/2020-TIP-Report-Complete-062420FINAL.pdf 
de personas en el período [2011-2019], las 3 principales nacionalidades fueron: boliviana $(28 \%)$, paraguaya $(25 \%)$ y colombiana $(14 \%)^{\prime \prime 39}$.

La segunda modalidad que utilizan los operadores del COT para el ingreso de extranjeros al país es el llamado "tráfico ilícito de migrantes». Este concepto se entiende como la facilitación de la entrada ilegal de una persona al territorio de Chile, siempre y cuando dicha persona no sea nacional o residente permanente con el fin de obtener, directa o indirectamente, un beneficio financiero $u$ otro beneficio de orden material.

La "entrada ilegal" se produce cuando se pasan los pasos fronterizos no habilitados, no se cumplen los trámites necesarios que permitan entrar legalmente en el país; o cuando se utilizan documentos falsificados o se falsea la identidad del extranjero que solicita el ingreso.

Para Chile, el problema también es importante y, a pesar de que la ley № 20.507 entrega atribuciones de control al gobierno es difícil conocer como opera el modelo del tráfico de migrantes, quienes lo ejecutan y que ganancias se llevan los operadores debido a que estas operaciones ilícitas son sigilosas, secretas y encubiertas.

No obstante que el tráfico de migrantes tiene estas características, los operativos policiales han permitido desbaratar algunas de las redes de traficantes, sobre todo en el norte del país, en la frontera con Perú.

Una de las redes más grandes que ha sido detectada por las autoridades policiales chilenas corresponde a la que traía a ciudadanos de la República Dominicana que llegaban irregularmente a Chile. Los migrantes generalmente viajaban primero a Ecuador o Colombia, y desde allí, hacia las partes septentrionales de Chile por tierra a través del Estado Plurinacional de Bolivia o Perú. El número de deportaciones de ciudadanos dominicanos debido a la entrada clandestina aumentó significativamente en Chile en 2015, pero sigue siendo muy bajo, con casi $600^{40}$.

El fiscal Emiliano Arias, coordinador de la Red Iberoamericana de Fiscales Especializados contra la Trata de Personas, explica que a los "...ciudadanos que son contactados en sus países por agencias o grupos criminales, les prometen mejores condiciones laborales. Luego, empleando un contacto falso en Chile, les entregan una carta de invitación que acredita que están de paso" ${ }^{41}$, agregando que "Las bandas dedicadas al tráfico de migrantes, según la fiscalía, pueden ganar desde US\$1.000 (\$ 490 mil) hasta US\$3.000 (\$1.470.000) por cada ilegal ingresado a Chile" ${ }^{42}$.

39 MINISTERIO DEL INTERIOR. Mesa Intersectorial de Trata de Personas. Datos 2011-2020. Santiago. 2021, p. 12 Disponible en: http://tratadepersonas.subinterior.gov.cl/media/2021/04/Informe-estadistico-sobre-Trata-de-Personas-2011-2020.pdf

40 ONU. United Nations Office on Drugs and Crime. Global Study on Smuggling of Migrants 2018. Nueva York. 2018. pp. 101-102. Disponible en: https://www.unodc.org/documents/data-and-analysis/glosom/ GLOSOM_2018_web_small.pdf

41 RODRÍGUEZ, S., LABRÍN, S., DÍAZ, F. y RIQUELME, P. (2013). La Tercera. 1 de junio 2013. Las rutas y el funcionamiento del tráfico de inmigrantes en Chile Santiago. Disponible en: https://www.latercera.com/noticia/ las-rutas-y-el-funcionamiento-del-trafico-de-inmigrantes-en-chile/

42 Ibíd. 
Entre los muchos casos sobre tráfico de migrantes que se pueden citar existen dos que son sorprendentes. El primero, corresponde a lo sucedido con 42 ciudadanos paquistaníes y, el segundo, al negocio de la Organización Gestiones Integrales SPA.

Los 42 ciudadanos paquistaníes fueron contactados por una agencia de viajes prometiéndoles visas para venir a Chile y luego pasar a EE. UU. y Canadá. La Fiscalía Occidente y la Policía de Investigaciones (PDI) acreditaron que todos pagaron US\$ 15 mil en Islamabad, capital de Paquistán, y que, una vez en el aeropuerto de Santiago, fueron llevados en bus a Iquique. "En esta ciudad terminaron como cargadores o vendedores en el recinto de la Zona Franca (Zofri) ${ }^{43}$.

El ilícito negocio de la Organización Gestiones Integrales SPA consistía en lo siguiente. Esta ilegal empresa la integraban 11 personas, de las cuales tres eran exautoridades públicas que crearon una red de trata de personas que introdujo en Chile a un importante número de ciudadanos chinos mediante cartas de invitación ideológicamente falsas ${ }^{44}$. Con estas cartas, pagadas a US $\$ 5.000$, por persona, los ciudadanos chinos podían obtener una visa de turismo para ingresar a Chile. La organización fue imputada por la Fiscalía por el ingreso ilegal de 381 ciudadanos chinos ${ }^{45}$.

Esta situación convierte al control de fronteras en la clave para determinar si la inmigración es legal o ilegal, pues los controles de identidad de las personas en las fronteras están destinados a detener el cruce de los migrantes que portan documentos de identidad falsos y. por lo tanto, son migrantes indocumentados.

Sin embargo, a los migrantes que se le niega el ingreso al país recurren, en la práctica, a otros medios: "...se las ingenian para burlar los controles corriendo mayores riesgos, cruzando a través de nuevas zonas fronterizas y recurriendo en gran medida a los profesionales del tráfico de personas" ${ }^{46}$.

Como una forma de enfrentar el problema, el gobierno, en junio de 2018, anuncio el inicio del llamado Plan de Frontera Norte 2.0 o Plan de Frontera Segura cuyo “...objetivo es fortalecer el control sobre las fronteras y, además, continuar trabajando con las cancillerías de los países vecinos para coordinar esfuerzos" ${ }^{\prime 7}$, que permitan controlar el flujo de migración irregular. De esta manera se pretendía asumir el control de la frontera nacional y poner en funcionamiento la llamada frontera externalizada.

43 Ibíd.

44 EL MOSTRADOR. 06.06.2019. Tráfico de migrantes: PDI detecta envío de más de USD 1 millón desde China a Chile. Disponible en https://www.elmostrador.cl/noticias/pais/2019/06/06/trafico-de-migrantes-pdi-detecta-envio-de-mas-de-usd-1-millon-desde-china-a-chile/

4524 HORAS.CL. 27.05.2019. Así operaba la mayor red de tráfico de migrantes en la historia de Chile. Disponible en: https://www.24horas.cl/nacional/asi-operaba-la-mayor-red-de-trafico-de-migrantes-en-la-historia-de-chile-3338793

46 PÉCOUD y GUCHTENEIRE. (2005). Op. Cit. p. 145.

47 EDICIÓN CERO. (2020). Gobierno anuncia mayor control de fronteras ante aumento de flujos migratorios. En el 2018 lanzó Plan Frontera Norte. Santiago. 29 septiembre 2020. Disponible en: https://edicioncero.cl/2020/09/gobierno-anuncia-mayor-control-de-fronteras-ante-aumento-de-flujos-migratorios-en-el-2018-lanzo-plan-frontera-norte/ 
Poco tiempo después se oficializó la información que, entre la frontera de Chile con Bolivia, en las regiones de Tarapacá y Antofagasta se detectaron 116 pasos no habilitados a los que se suman los 50 identificados en la frontera con Perú, sumando en total 166 pasos no habilitados en la MacroZona Norte del país ${ }^{48}$.

Las entradas ilegales de migrantes al país durante 2019 presentaron un alza constante, alcanzando la suma de 4.255 casos en el primer semestre. Integraban este grupo de migrantes ilegales 1.536 venezolanos, 928 cubanos, 831 dominicanos, 442 bolivianos y 230 colombianos mientras que los inmigrantes de otras nacionalidades sumaban 288 individuos ${ }^{49}$.

Consultada la fiscal regional de Arica y Parinacota, Javiera López, especialista en delitos de tráfico de migrantes señala que, "En la región estos ilícitos son perseguidos por la unidad de Alta Complejidad, ya que se trata de organizaciones criminales transnacionales", agregando que se ha "detectado un significativo incremento en casos de tráfico de migrantes... que se concentran en víctimas de nacionalidad venezolana"

Con relación a la forma que operan las organizaciones criminales o "los coyotes", para realizar el ingreso ilegal de migrantes la Fiscal López manifiesta que

Hemos detectado que los miembros operativos o "coyotes", que son quienes los guían en su ingreso al país, están dejando abandonadas a las víctimas migrantes en pleno trayecto, para evitar ser detenidos. Los imputados les indican a las víctimas que deben seguir determinada ruta y los dejan solos. Ahí es cuando se produce el mayor riesgo para las víctimas, ya que deambulan desorientadas por el desierto, durante la noche o a plena luz del sol y con temperaturas extremas. Para las organizaciones se trata de traficar con objetos, en vez de seres huma$\operatorname{nos}^{51}$.

La presencia del Corona Virus (COVID-19) en el mundo y la declaración de pandemia por la Organización Mundial de la Salud (OMS), complicó el panorama de la migración en todo el país y, en particular en la macrozona norte. Para evitar un contagio comunitario, el Gobierno decidió cerrar todas las fronteras terrestres, marítimas y aéreas del país para el tránsito de personas extranjeras. Sin embargo, esta medida presentó varios problemas en el panorama migratorio:

48 RADIO ADN. Detectan 166 pasos fronterizos no habilitados en el norte de Chile. Santiago, 9 de julio 2018. Disponible en: https://www.adnradio.cl/nacional/2018/07/09/detectan-166-pasos-fronterizos-no-habilitados-en-el-norte-de-chile-3771604.html

49 AGENCIA EFE. El ingreso ilegal de inmigrantes a Chile alcanza una cifra récord en 2019. 25 julio 2019. Disponible en: https://www.efe.com/efe/america/sociedad/el-ingreso-ilegal-de-inmigrantes-a-chile-alcanza-una-cifra-record-en-2019/20000013-4030507

50 MIGRACIÓN EN CHILE. Tráfico de migrantes sube 53\% y $91 \%$ de extranjeros ingresados ilegalmente tiene educación media y superior completa. Una plataforma del Servicio Jesuita de Migrantes. Disponible en: https://www.migracionenchile.cl/trafico-de-migrantes-sube-53-y-91-de-extranjeros-ingresados-ilegalmente-tiene-educacion-media-y-superior-completa/

51 Ibíd. 
aumento de la migración clandestina y el riesgo del tráfico de personas; inmovilización de los migrantes en tránsito que no tienen donde quedarse; paralización de las economías fronterizas de las que dependen cientos de miles de personas; y dificultad de retorno de migrantes que prefieren regresar a su país ante la crisis generada por el COVID-1952.

A pesar del cierre de fronteras, la vulnerabilidad de los controles fronterizos quedó en evidencia al constatar que hasta agosto de 2020 habían ingresado al país 5.147 inmigrantes en forma irregular, siendo el grupo más numeroso los venezolanos que llegaba a 2.969 en este $a n ̃ 0^{53}$. Asimismo, el Servicio Jesuita Migrantes Chile (SJM), con información oficial de la Policía de Investigaciones, confirmó que durante todo 2019 se contabilizaron 8.048 ingresos clandestinos y que entre enero y julio de 2020 se registraron 3.949 ingresos por pasos no habilitados ${ }^{54}$.

Las estadísticas de ingreso y egreso de transeúntes que cruzan o salen por el paso de control fronterizo chileno de Colchane, muy cercano al paso fronterizo de Pisiga, en Bolivia, se presentan en la Tabla № 2

\section{Tabla № 2}

PASO FRONTERIZO DE COLCHANE

Ingreso y Egreso de Transeúntes 2018-2020

\begin{tabular}{|c|c|c|c|c|}
\hline Año & Ingreso & Egreso & Diferencia & Total Movimiento \\
\hline 2018 & 417.925 & 348.831 & 69.094 & 766.756 \\
\hline 2019 & 453.544 & 388.838 & 64.706 & 842.382 \\
\hline 2020 & 126.290 & 123.146 & 3.144 & 249.436 \\
\hline
\end{tabular}

FUENTE: Elaboración propia con Información de la Oficina PDI. Santiago. Datos 2020, entre enero y junio.

Considerando la gravedad del problema, en agosto 2020 el ministro del Interior Víctor Pérez viajó al norte del país para conocer en terreno el funcionamiento del Plan Frontera Segura que, desde 2018, tiene como propósito disminuir la permeabilidad de las fronteras ante el crimen organizado transnacional y como misión "...controlar más de un centenar de pasos ilegales ubicados en la macrozona norte del país, a fin de evitar la comisión de ilícitos

52 LA MALETA ABIERTA. Migrantes y COVID-19: ¿Qué están haciendo los países de América Latina con más migrantes para apoyarlos durante la pandemia? Disponible en: https://blogs.iadb.org/migracion/es/migrantes-y-covid-19-que-estan-haciendo-los-paises-de-america-latina-con-mas-migrantes-para-apoyarlos-durante-la-pandemia/

53 EDICIÓN CERO. (2020). Loc. Cit.

54 SERVICIO JESUITA MIGRANTES CHILE (SJM). Urge regular ingreso migratorio por complejo fronterizo Colchane. 2020. Disponible en: https://sjmchile.org/2020/10/20/urge-regular-ingreso-migratorio-por-complejo-fronterizo-colchane/ 
como tráfico de drogas, contrabando, trata de personas, comercialización de vehículos robados o ingresos ilegales de migrantes" ${ }^{\prime 55}$.

La situación general de la zona fronteriza ubicada entre el control de Colchane y el de Pisiga es particularmente complicada porque existe una franja de límite con varios pasos fronterizos no habilitados que utilizan frecuentemente los traficantes de personas (los llamados "coyotes") para evadir los controles fronterizos oficiales, tanto del lado chileno como boliviano.

Al mismo tiempo, la situación del cruce de fronteras de la población migrante ya sea por pasos legales o pasos ilegales, especialmente en esta zona, convierten a los controles fronterizos en un eje vulnerable de la seguridad interna del país porque constituyen el lugar geográfico ubicado en el Límite Político Internacional (LPI) por donde es posible el tránsito de entrada y salida terrestre del país. Esta oportunidad es aprovechada por los agentes del Crimen Organizado Transnacional (COT), empleando dos vías para comerciar con las necesidades de los migrantes: la trata de personas y el tráfico de migrantes.

Los traficantes aprovechan las necesidades de los migrantes para ofrecerles una vía para cruzar la frontera. Esta vía es el negocio de la trata de personas, realizada por un operador que ofrece falsas promesas de trabajo a personas que quieren migrar hacia Chile bajo ciertas condiciones que no implican consentimiento efectivo, pero que luego se transforman en amenazas y obligaciones de las que no pueden evadirse. Además, los informes de la Fiscalía señalan que el tráfico ilícito de migrantes se formaliza cuando un traficante, por medio de un elevado pago, posibilitará la entrada ilegal al migrante al país. Posiblemente, cuando el individuo llegué a la frontera el "coyote" le indicará los caminos a seguir y romperá los lazos de contacto con el migrante.

En consecuencia, no cabe duda de que los operadores que manejan estos negocios y son responsables de estos crímenes pertenecen o están asociados al COT; razón fundamental para entender la falta de datos seguros que permitan denunciar estas actividades delictuales que son silenciosas, casi invisibles, que forman parte de una economía informal muy rentable y con un bajo perfil de riesgo. Por lo mismo, se complejiza el control de las fronteras tanto en los aspectos de los ingresos de personas como de mercaderías y bienes.

En noviembre 2020, el ministro de Defensa Mario Desbordes en su visita a la región de Tarapacá reconoció las dificultades que se presentan para vigilar los más de mil kilómetros de territorios fronterizos ya que por los pasos habilitados y no habilitados de Arica, desde Perú, y por Colchane, desde Bolivia, ingresan inmigrantes ilegales, a los cuales se suma al tráfico de drogas y el contrabando. ${ }^{56}$.

El ministro del Interior Rodrigo Delgado en diciembre 2020 se reunió en Antofagasta con las autoridades locales para conocer la situación de la macrozona Norte. En esa oca-

55 EMOL. Ministro Pérez anuncia fortalecimiento del plan Frontera Segura ante "agravamiento de la situación migratoria". 8 de agosto 2020. Disponible en: https://www.emol.com/noticias/Nacional/2020/08/08/994416/Perez-fortalecimiento-Plan-Frontera-Segura.html

56 JAIME, Davied y ROJAS, Mario. El Mercurio. 25 de noviembre de 2020. p. C9. Migración ilegal, tráfico de drogas y contrabando revelan la fragilidad de la extensa frontera con Perú y Bolivia. Santiago. Disponible en: https://digital.elmercurio.com/2020/11/25/C/RH3SMEI4\#zoom=page-width 
sión, el ministro declaró que esta reunión de coordinación permitía "poder definir las estrategias para combatir el crimen organizado" ${ }^{57}$. Al ser consultado sobre el ingreso irregular de migrantes precisó que

Son cinco pasos habilitados que por la pandemia no están todos operativos, pero también hay decenas de pasos irregulares y eso genera un tremendo desafío. Nos hemos dado cuenta de un trabajo efectivo que se está realizando en la frontera. El desafío es gigante. Al haber tanto paso irregular y Chile ser un país atractivo para la migración tenemos un desafío. No solamente tenemos que hacer un trabajo efectivo, sino que también contar con más y mejores herramientas. Es por eso por lo que valoramos la nueva Ley de Migraciones. Esta nueva ley entregará herramientas para que nuestras policías y Fuerzas Armadas la aprovecharán de mejor manera ${ }^{58}$

La ley a que se refiere el ministro es la que regulará el proceso migratorio a Chile, aprobada por el Senado de la República en diciembre de $2020^{59}$. Esta ley considera iniciativas que incorporan normas para resguardar los derechos humanos de los migrantes y los derechos del Estado de Chile.

Posteriormente, el 12 enero de 2021, se modificó el decreto 265 de 2019 que autorizaba a las Fuerzas Armadas para apoyar el control de fronteras en materias de narcotráfico y crimen organizado y que, a partir de esta fecha amplió "...su objeto y permite el control del tráfico ilícito de migrantes y trata de personas por pasos no habilitados en las regiones de Arica y Parinacota, Tarapacá y Antofagasta"60.

Sin embargo, en los meses que siguieron a la firma de este decreto los ingresos ilegales continuaron y el aumento del tráfico de migrantes fue significativo. Este flujo de migración traficada corresponde, principalmente, a ciudadanos venezolanos, lo cual podría explicarse por la situación social que afecta a ese país y la pandemia del Covid-19.

Entre los casos de ingreso ilegal correspondientes a tráfico de migrantes se destaca el que ocurrió a principios del mes de marzo 2021 cuando Carabineros de Chile detuvo a tres personas de nacionalidad chilena por el delito de tráfico de migrantes. Los detenidos, fueron sorprendidos y detectados en la Ruta $15 \mathrm{CH}$ circulando en un camión tras cruzar por un paso fronterizo no habilitado. "Entre los 27 migrantes, la mayoría venezolanos, había

57 GOB.CL. Ministro Delgado encabeza reunión de la Macro Zona Norte en Antofagasta. 10 diciembre 2020. Disponible en: https://www.gob.cl/noticias/ministro-delgado-encabeza-reunion-de-la-macro-zona-norte-en-antofagasta/

58 Ibíd.

59 El jueves 3 de diciembre de 2020 el Senado de la República despachó aprobado el proyecto de la nueva Ley de Migraciones, ingresada al Parlamento en 2013. No obstante, a esta aprobación, algunos parlamentarios plantearon que pedirían reserva de constitucionalidad. Al momento de cerrar este artículo, el 20 abril de 2021 se publicó en el Diario Oficial la Ley № 21.325 como Ley de Migraciones

60 GOB.CL. Presidente firma decreto que permite a las Fuerzas Armadas apoyar el control del tráfico ilícito de personas. 12 de enero 2021. Disponible en:

https://www.gob.cl/noticias/presidente-firma-decreto-que-permite-a-las-fuerzas-armadas-apoyar-el-control-del-trafico-ilicito-de-personas-estamos-comprometidos-con-poner-orden-en-nuestra-casa-proteger-mejor-nuestras-fronteras-y-combatir-la-inmigracion-ilegal/ 
cinco menores de edad. Durante el procedimiento, se incautaron tres vehículos, teléfonos celulares y dinero en efectivo" ${ }^{\prime \prime}$.

A pesar de los controles fronterizos y las restricciones impuestas para frenar el cruce ilegal de la frontera las redes transnacionales dedicadas al tráfico de personas han seguido funcionando. Pero, como es de conocimiento público, lo más grave que se ha producido con este tipo de cruces ilegales es que hasta fines del mes de marzo 2021 habían fallecido seis migrantes en las cercanías del complejo Fronterizo de Colchane. Una muestra de la forma en que trabajan los antisociales del tráfico humano es la muerte de una mujer migrante venezolana, de 32 años, que tras intentar ingresar de manera irregular a Chile "fue abandonada por el "coyote» que trasladaba a un grupo de migrantes ilegales, debido a su mal estado de salud"62,

Por todas estas circunstancias las autoridades chilenas han intensificado el monitoreo constante de los pasos fronterizos informales o no habilitados con el propósito de controlar el ingreso ilegal de los extranjeros y combatir al mismo tiempo las actividades comerciales ilícitas, como el tráfico de drogas y el contrabando.

\section{CONCLUSIONES}

La migración como fenómeno histórico y estructural, ya forma parte de la globalización y siempre estará presente en la realidad de los países independientemente del tipo de políticas que manejen para controlar el flujo migratorio

En el caso de Chile, que se ha convertido, en los últimos años, en país de destino de migrantes transfronterizos y regionales, es preciso que las políticas que se apliquen estén equilibradas y consideren los derechos soberanos del país, los aspectos de la seguridad interna, especialmente frente a la trata de personas y el tráfico de migrantes y las necesidades de integración de los migrantes.

Desde luego, frente a la posibilidad de establecer controles fronterizos que prohíban el ingreso de migrantes, las líneas que orienten la renovación de la política migratoria del país deben estar en consonancia con el actual carácter que tienen las migraciones en el marco de la globalización y mundialización de la economía. Eso significa que la futura política migratoria nacional anunciada en la nueva ley de migraciones deberá asumir una actitud de respeto de los derechos humanos de los migrantes. Pero, al mismo tiempo, deberá proteger la soberanía del país instalando requisitos para controlar y cautelar la entrada, permanencia y tránsito de los migrantes por el territorio chileno buscando un equilibrio con los derechos y deberes que el derecho internacional otorga a los migrantes.

Por otra parte, el aumento del flujo de migrantes que ingresa al país por la frontera de la macrozona norte del país, que en algunas ocasiones ha llegado a confundirse con el tráfico de migrantes y la trata de personas porque estas dos actividades ilícitas la desarro-

61 PEÑA, J. El Mercurio. 11 de marzo 2021. Detienen a tres personas por tráfico de migrantes en lquique: Entre los extranjeros había cinco menores de edad. Disponible en: https://www.emol.com/noticias/Nacional/2021/03/11/1014562/Detienen-personas-migrantes-pasos-ilegales.html

62 T13.CL. Muere mujer migrante tras intentar ingresar de manera irregular a Chile. 23 de marzo 2021. Disponible en: https://www.t13.cl/noticia/nacional/inmigrante-murio-intentar-ingresar-manera-irregular-chile-23-03-2021 
Ilan los "coyotes" por pasos no habilitados, ha llevado a las autoridades a intensificar los controles fronterizos migratorios.

En consecuencia, la nueva política migratoria de Chile no debe considerar movimientos de población sin control fronterizo, muy por el contrario, debe asegurar los factores que protejan dichos movimientos con los principios de la migración segura, ordenada, regular y responsable. 


\section{REFERENCIAS BIBLIOGRÁFICAS}

\section{Libros y Artículos}

ARMIJO Canto, Natalia. Introducción. En: N. Armijo Canto (Ed.) Migración y seguridad: nuevo desafío en México. Colectivo de Análisis de la Seguridad con Democracia A.C. (CASEDE). Disponible en: https://www.casede.org/PublicacionesCasede/MigracionySeguridad/pda.pdf , México. 2011, p. 7

BAGGIO, Fabio. Fronteras nacionales, internalizadas y externalizadas. En Anguiano Téllez, María Eugenia y López Sala, Ana María (Ed). Migraciones y fronteras: nuevos contornos para la movilidad internacional, Barcelona, Icaria Antrazyt/CIDOB, 2010, pp. 49-74.

BRAVO, Guillermo. "Chile ¿Migraciones sin fronteras?”. En: Revista Migrante 2020, № 77, pp. 33-36. Disponible en: https://incami.cl/wp-content/uploads/2020/04/Revista-Migrantes-No.-77.pdf

BRAVO, Guillermo. La política migratoria de Chile en tiempos de la globalización y la "Nueva Migración". En: Desafíos de la Seguridad y Defensa en el mundo contemporáneo. Libro Colección ANEPE No 39. Santiago. 2016. Disponible en: https://anepe.cl/wp-content/uploads/2020/10/LIBRO-ANEPE-39.pdf

BRAVO, Guillermo y Norambuena, Carmen. Procesos Migratorios en Chile. Una mirada histórica normativa. Libro Colección ANEPE № 43. Santiago. 2018. Disponible en: https://anepe.cl/wp-content/uploads/2020/10/LIBRO-ANEPE-43.pdf

BRETONES, F. D. y GONZÁLEZ-GONZÁLEZ, J. M. "Identidad y migración: la formación de nuevas identidades transculturales", En: H. M. Cappello y M. Recio (Eds.). La Identidad Nacional. Sus Fuentes Plurales de Construcción. Plaza y Valdés Editores. México. 2011. Disponible en: https://www.academia.edu/4577111/Identidad_y_migraci\%C3\%B3n_la_formaci\%C3\%B3n_de_nuevas_identidades_transculturales

BRICEÑO Monzillo, José Manuel. Nuestras fronteras con Colombia. Universidad de Los Andes. Mérida. 1982, p. 130.

ESCOBAR, Leyla (s.f.). La inmigración en Chile: La necesidad de un Plan Nacional de Integración. y Cooperación Internacional. Diario Constitucional.cl. Santiago. Disponible en: https://www.diarioconstitucional.cl/articulos/la-inmigracion-en-chile-la-necesidad-de-un-plan-nacional-de-integracion-y-cooperacion-internacional/

ESPALIAT Larson, Astrid. Fronteras y límites. Una mirada desde el Derecho Internacional. Instituto de Estudios Internacionales. Universidad de Chile. 2011. Disponible en: http://iei.uchile.cl/noticias/70662/fronteras-y-limites-una-mirada-desde-el-derecho-internacional

GONZÁLEZ Miranda, Sergio. La voz desde Lejos. La triple-frontera andina: Entre la heterología y la globalización. En: Andamios. Revista de Investigación Social. Vol. 12. № 28. Colegio de Humanidades y Ciencias Sociales, Universidad Autónoma de la Ciudad 
de México. 2015. Disponible en: http://www.scielo.org.mx/pdf/anda/v12n28/18700063-anda-12-28-00019.pdf

JAIME, Davied y ROJAS, Mario. El Mercurio. 25 de noviembre de 2020. p. C9. Migración ilegal, tráfico de drogas y contrabando revelan la fragilidad de la extensa frontera con Perú y Bolivia. Santiago. Disponible en: https://digital.elmercurio.com/2020/11/25/C/ RH3SMEI4\#zOom=page-width

LÓPEZ Jiménez, A. El arte en la calle. En: Reis: Revista Española de Investigaciones Sociológicas. 1998, №. 84, pp. 173-194. en: https://dialnet.unirioja.es/servlet/autor?codigo $=67901$

NORAMBUENA, Carmen. "Frontera, Fronteras, Límites y Trasgresiones": En: Cuadernos de Historia No 20. Universidad de Chile. Santiago. 2000.

PÉCOUD, Antoine y GUCHTENEIRE, Paul de. Migración sin fronteras: una investigación sobre la libre circulación de personas En: Migraciones Internacionales, Vol. 3, Núm. 2. Tijuana. 2005. Disponible en: http://www.scielo.org.mx/pdf/migra/v3n2/v3n2a6.pdf

PEÑA, J. El Mercurio. 11 de marzo 2021. Detienen a tres personas por tráfico de migrantes en lquique: Entre los extranjeros había cinco menores de edad. Disponible en: https://www.emol.com/noticias/Nacional/2021/03/11/1014562/Detienen-personas-migrantes-pasos-ilegales.html

RANFLA González, Arturo. Frontera política y espacio fronterizo. En: Estudios Fronterizos Año II, Vol. I, N.o 4-5. Instituto de Investigaciones Sociales. Universidad Autónoma de Baja California. 1984. p 50. Disponible en: http://ref.uabc.mx/ojs/index.php/ref/ article/view/383

RODRÍGUEZ, S., LABRÍN, S., DÍAZ, F. y RIQUELME, P. La Tercera. 1 de junio 2013. Las rutas y el funcionamiento del tráfico de inmigrantes en Chile Santiago. Disponible en: https:// www.latercera.com/noticia/las-rutas-y-el-funcionamiento-del-trafico-de-inmigrantes-en-chile/

\section{Documentos}

BIBLIOTECA DEL CONGRESO NACIONAL. (BCN). Ministerio del Interior. Subsecretaría del Interior. Aprueba Reglamento de la Ley № 20.430, que establece disposiciones sobre protección de refugiados. 2011. Disponible en: https://www.extranjeria.gob.cl/media/2019/03/DTO-837_17-FEB-2011_Reglamento_Refugio.pdf

BCN. Gobierno de Chile. Decreto Ley N 1094, D.O. 19 de julio de 1975. Disponible en: https://www.bcn.cl/leychile/navegar?idNorma=6483\&idVersion=2011-04-08\&buscar $=1094$

DEPARTMENT OF ESTATE. United States of América. Trafficking in Persons Report 20th Edition. 2020. Disponible en: https://www.state.gov/wp-content/uploads/2020/06/2020TIP-Report-Complete-062420-FINAL.pdf 
INSTITUTO NACIONAL DE ESTADÍSTICAS. (INE). Censos de Población 1982-2012. Disponible en: www.http://historico.ine.cl/canales/chile_estadistico/censos/censo_poblacion_ vivienda.php

GOB.CL. Ministro Delgado encabeza reunión de la Macro Zona Norte en Antofagasta. 10 diciembre 2020. Disponible en: https://www.gob.cl/noticias/ministro-delgado-encabeza-reunion-de-la-macro-zona-norte-en-antofagasta/

GOB.CL. Presidente firma decreto que permite a las Fuerzas Armadas apoyar el control del tráfico ilícito de personas. 12 de enero 2021. Disponible en: https://www.gob. $\mathrm{cl} /$ noticias/presidente-firma-decreto-que-permite-a-las-fuerzas-armadas-apoyar-el-control-del-trafico-ilicito-de-personas-estamos-comprometidos-con-poner-orden-en-nuestra-casa-proteger-mejor-nuestras-fronteras-y-combatir-la-inmigracion-ilegal/

GOBIERNO DE CHILE. Gabinete de la Presidencia. Imparte instrucciones sobre la Política Nacional de Migraciones 2 de septiembre de 2008 Disponible en: https://www.extranjeria.gob.cl/media/2019/03/Inst-Presidencial-NNo-9.pdf

MINISTERIO DE DEFENSA NACIONAL (MDN). Libro de la Defensa. Santiago. 2010.

MINISTERIO DEL INTERIOR DE CHILE. Mesa Intersectorial de Trata de Personas. Datos 2011-2020. 2021 Disponible en: http://tratadepersonas.subinterior.gov.cl/media/2021/04/Informe-estadistico-sobre-Trata-de-Personas-2011-2020.pdf 12.

ORGANIZACIÓN INTERNACIONAL PARA LAS MIGRACIONES. (OIM). 2006. Glosario sobre Migración. En: Derecho Internacional sobre Migraciones № 7. Ginebra. Disponible en: https://publications.iom.int/system/files/pdf/iml_7_sp.pdf

OIM. (s.f.). Inmigración y gestión de fronteras. Disponible en: https://www.iom.int/es/inmigracion-y-gestion-de-fronteras

ORGANIZACIÓN DE LAS NACIONES UNIDAS (ONU). International Migration Report 2017. Disponible en: https://www.un.org/en/development/desa/population/migration/ publications/migrationreport/docs/MigrationReport2017_Highlights.pdf

ONU. United Nations Office on Drugs and Crime. Global Study on Smuggling of Migrants 2018. Nueva York. 2018. Disponible en: https://www.unodc.org/documents/data-and-analysis/glosom/GLOSOM_2018_web_small.pdf

ONU. Declaración Universal de los Derechos Humanos. En: Museo de la Memoria y los Derechos Humanos. Área de Educación. Santiago. 1948. Disponible en http://www. museodelamemoria.cl/wp-content/uploads/2011/09/DECLARACIÓN-UNIVERSAL-DE-LOS-DERECHOS-HUMANOS.pdf

ONU. Carta de las Naciones Unidas. 1945. Disponible en: https://www.un.org/es/sections/ un-charter/chapter-i/index.html

DICCIONARIO DE LA REAL ACADEMIA (RAE). 2019. Disponible en: https://dle.rae.es/l\%C3\%ADmite 
SERVICIO JESUITA MIGRANTES CHILE (SJM). Urge regular ingreso migratorio por complejo fronterizo Colchane. 2020 Disponible en: https://sjmchile.org/2020/10/20/urge-regular-ingreso-migratorio-por-complejo-fronterizo-colchane/

\section{Prensa}

AGENCIA EFE. El ingreso ilegal de inmigrantes a Chile alcanza una cifra récord en 2019. 25 julio 2019. Disponible en: https://www.efe.com/efe/america/sociedad/el-ingreso-ilegal-de-inmigrantes-a-chile-alcanza-una-cifra-record-en-2019/20000013-4030507

EDICIÓN CERO. Gobierno anuncia mayor control de fronteras ante aumento de flujos migratorios. En el 2018 lanzó Plan Frontera Norte. Santiago. 29 septiembre 2020. Disponible en: https://edicioncero.cl/2020/09/gobierno-anuncia-mayor-control-de-fronteras-ante-aumento-de-flujos-migratorios-en-el-2018-lanzo-plan-frontera-norte/

EMOL. Ministro Pérez anuncia fortalecimiento del plan Frontera Segura ante «agravamiento de la situación migratoria». 8 de agosto de 2020. Disponible en: https://www. emol.com/noticias/Nacional/2020/08/08/994416/Perez-fortalecimiento-Plan-Frontera-Segura.html

EL MOSTRADOR. 06.06.2019. Tráfico de migrantes: PDI detecta envío de más de USD 1 millón desde China a Chile. Disponible en: https://www.elmostrador.cl/noticias/ pais/2019/06/06/trafico-de-migrantes-pdi-detecta-envio-de-mas-de-usd-1-millondesde-china-a-chile/

LA MALETA ABIERTA. Migrantes y COVID-19: ¿Qué están haciendo los países de América Latina con más migrantes para apoyarlos durante la pandemia? Disponible en: https:// blogs.iadb.org/migracion/es/migrantes-y-covid-19-que-estan-haciendo-los-paises-de-america-latina-con-mas-migrantes-para-apoyarlos-durante-la-pandemia/

MIGRACIÓN EN CHILE. Tráfico de migrantes sube 53\% y 91\% de extranjeros ingresados ilegalmente tiene educación media y superior completa. Una plataforma del Servicio Jesuita de Migrantes. Disponible en: https://www.migracionenchile.cl/trafico-de-migrantes-sube-53-y-91-de-extranjeros-ingresados-ilegalmente-tiene-educacion-media-y-superior-completa/

RADIO ADN. Detectan 166 pasos fronterizos no habilitados en el norte de Chile. Santiago, 9 de julio 2018. Disponible en: https://www.adnradio.cl/nacional/2018/07/09/detectan-166-pasos-fronterizos-no-habilitados-en-el-norte-de-chile-3771604.html

T13.CL. Muere mujer migrante tras intentar ingresar de manera irregular a Chile. 23 de marzo 2021. Disponible en: https://www.t13.cl/noticia/nacional/inmigrante-murio-intentar-ingresar-manera-irregular-chile-23-03-2021

24 HORAS.CL. 27.05.2019. Así operaba la mayor red de tráfico de migrantes en la historia de Chile. Disponible en: https://www.24horas.cl/nacional/asi-operaba-la-mayor-redde-trafico-de-migrantes-en-la-historia-de-chile-3338793 